\section{Parkinson's researchers join forces with gene tester}

The Parkinson's Institute and Clinical Center in Sunnyvale, California, last week announced an alliance with 23 andMe, a gene-testing company in Mountain View, California. The initiative aims to improve methods for collecting large amounts of consistent data on DNA, lifestyle, family history and environmental exposures, to unpick the factors that contribute to Parkinson's disease.

The current initiative, funded by the Michael J. Fox Foundation for Parkinson's Disease, will gather information from 150 people - half with and half without the disease. Researchers will use questionnaire data from the group to develop robust surveys that can be hosted online by 23andMe. The idea is that future 23andMe clients will be offered the chance to take these surveys, so they can easily add their genetic and lifestyle data to the project.

"It could be a real game change" for disease epidemiology, says Bill Langston, director of the Parkinson's Institute. But he acknowledges that it will only have a big impact if many people choose to pay for the genetic tests and participate in studies.

\section{Europe considers plans for manned spacecraft}

The European Space Agency (ESA) is mulling over the idea of turning its latest cargo ship into a manned spacecraft.

Launched for the first time in March, the Automated Transfer Vehicle is a 20-tonne vessel for carrying food, water, oxygen and experiments to the International Space Station. It is designed to burn up on re-entry after its mission is completed. But later this week, the ship's manufacturer, Paris-based aerospace giant EADS Astrium, is expected to announce detailed plans for turning it into a manned spacecraft. The design would include a re-entry capsule for three people

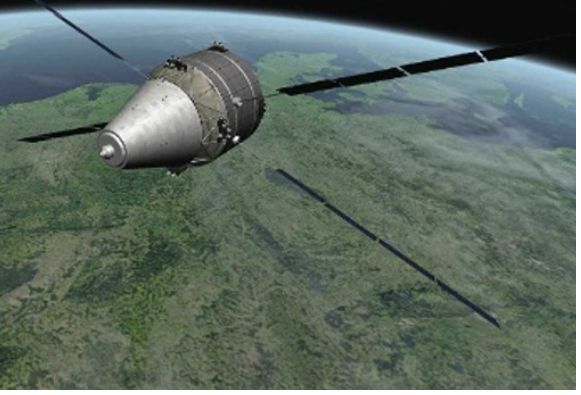

An artist's impression of the Automated Transfer Vehicle fitted with a return capsule.

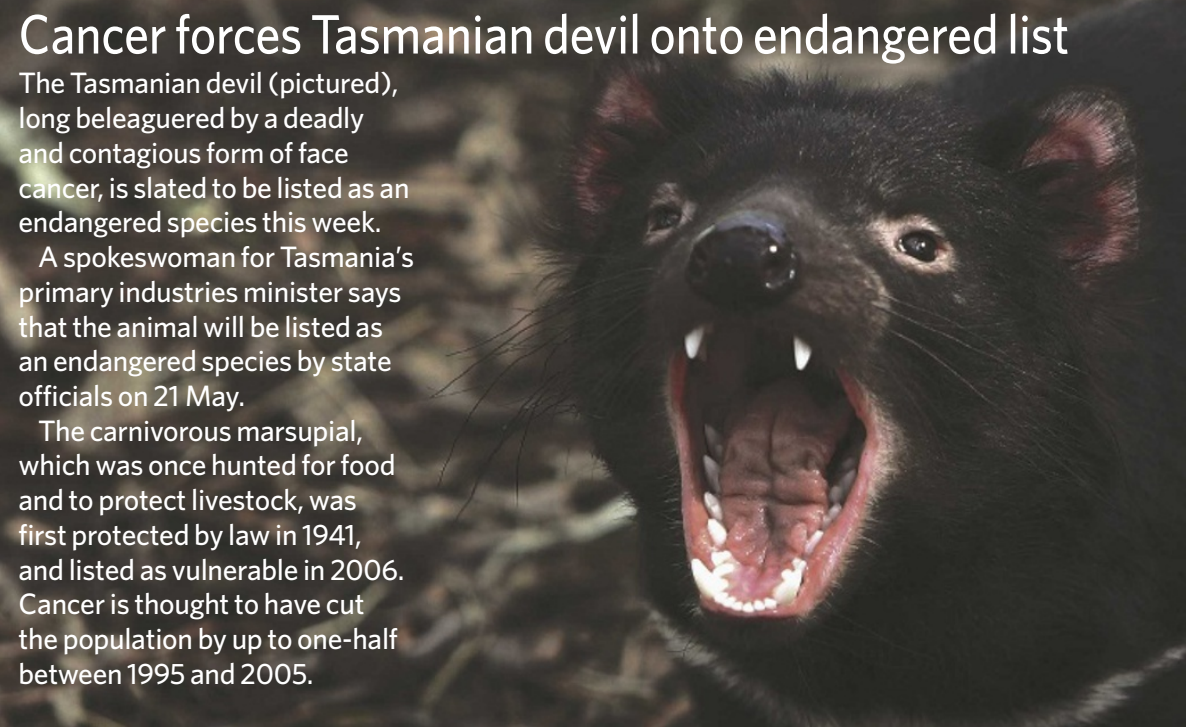

and new safety features.

ESA is taking the proposal seriously, says Manuel Valls, head of policy and planning for the agency's human spaceflight directorate in Noordwijk, the Netherlands. At present, Europe depends on the United States and Russia to transport people into space. Valls says the new craft would probably cost several billion euros to develop. ESA's governing council is expected to review the proposal in November, along with other options.

\section{British parliament backs hybrid embryos}

UK politicians have rejected calls to ban the creation of animal-human hybrid embryos. In a key vote on 19 May, parliamentarians voted by $336-176$ in favour of allowing the creation of 'cybrid' embryos, those created from human DNA and an empty animal egg. They also favoured the creation of 'true' genetic animal-human hybrid embryos, purely for research purposes, by the narrower margin of 286 to 223.

Parliamentarians were given a 'free' vote, rather than being whipped along party lines, on the most controversial aspects of a raft of proposed new fertility legislation. The entire bill, after further votes on aspects such as Britain's current abortion limit of 24 weeks, will be voted on as a whole in coming months.

\section{Cosmic dust hides true brightness of Universe}

The Universe may be brighter than thought: perhaps twice as bright as seen from Earth.

Interstellar cosmic dust absorbs some starlight, but quantifying this has proved difficult. Researchers from the United Kingdom, Germany and Australia looked closely at how dust obscures light in some nearby galaxies, depending on various factors including the size, shape and inclination of the galaxy. They used these data to make a better model of how dust absorbs light, and applied the model to a catalogue of 10,000 galaxies.

The result suggests that dust is blocking nearly half of this light from our view, making the true brightness of the nearby Universe nearly twice that seen from Earth (S. P. Driver et al. Astrophys. J. Lett. 678, L101-L104; 2008). The researchers say that their findings could force a revision in mass estimates for dust-shrouded galaxies, and a reconsideration of models of galaxy formation in the early Universe.

\section{NOAA chief backs bid for climate-change agency}

The chief of the US National Oceanic and Atmospheric Administration (NOAA) has called for the creation of a National Climate Service to manage and disseminate information about global warming.

Like the National Weather Service, the service would fall within NOAA and be a repository for federal research that would be accessible to agencies and the public alike. NOAA administrator Conrad Lautenbacher says that having a central scientific organization to collate this information could help to depoliticize climate research. The service would not have any regulatory authority.

The Senate Committee for Commerce, Science and Transportation passed legislation by John Kerry (Democrat, Massachusetts) to create such a Climate Service last December. Lautenbacher says that the White House supports the idea in principle. NOAA plans to seek funding to organize the service in the 2010 budget proposal. 